\title{
Estimating Cost Savings when Implementing a Product Platform Approach
}

\author{
Zahed Siddique ${ }^{1, *}$ and Bill Repphun ${ }^{2}$ \\ ${ }^{1}$ School of Aerospace and Mechanical Engineering University of Oklahoma, Norman, OK 73019, USA \\ ${ }^{2}$ Advanced Concepts Group, Seagate Technology Inc., Longmont, CO 80503, USA
}

\begin{abstract}
Many market forces are driving companies to improve their targeting of increasingly small market niches. To accomplish this efficiently, products are organized into product families that typically share common platforms. To reorganize the current product offerings or new products into a product family, using a platform approach, requires estimating the savings for such a modification. One of the problems encountered in estimating development and design cost is the lack of availability of hard information during the initial design phases. The purpose of this paper is to estimate the design and development cost, when moving towards a platform approach, using simple models. The activity based product family cost models are developed from existing single product design activities, which are modified and extended to reflect activities related to development of product platform and subsequent product family members supported by the platform. Uncertainty related to cost associated with activities are included in the model, which is solved using Monte Carlo simulation. The approach is demonstrated using a hard disk drive spindle motor platform development for a family of hard disks.
\end{abstract}

Key Words: product family design, cost estimation, activity based costing.

\section{Introduction}

Companies are striving to deliver greater quality, more customization, faster response, more innovative design and lower prices [1,2]. New models are introduced in the market more frequently and the number of mass-produced models is decreasing [3]. The new shift in the current market has introduced the concept of product family design, in which variety and customization replace standardized products. Designing a family of products starts with a good platform approach. "A product platform is a collection of the common elements, especially the underlying core technology, implemented across a range of products," [4]. A platform approach for a product family provides a common base that can be used to design, develop and produce multiple products. Focusing product strategy at the platform level simplifies the product development process, because there are fewer platforms than products and major platform decisions are only made every few years. A platform approach encourages a long-term view of the product strategy.

As a company moves towards design and development of a product family, using a platform approach, one of the key questions that need to be addressed is: What will be the financial effect of moving toward a product family approach? To address this question, product design and development cost for using a platform approach needs to be determined. One of the problems encountered is that cost information related to product platform and family are not readily available. Available information includes cost data associated with development of a single product. Activities involved in design and development of products have inherent uncertainty associated with them, which needs to be included in the models. The purpose of this paper is to develop cost models to approximate development cost and financial effects related to implementing a product family approach.

In the next section, research related to product family design and Activity Based Cost (ABC) models are discussed. In Section 3, the overall approach to building ABC model for product family is presented. In Section 4 a hard disk spindle motor development case study is presented to approximate development cost for product family and potential savings for moving toward a platform approach. Concluding remarks are discussed in the last section.

\footnotetext{
*Author to whom correspondence should be addressed.
} 


\section{Related Work}

\subsection{Product Family Design}

Different approaches to provide families of products through the use of common platforms have been proposed. Wheelwright and Clark [5] suggest designing "platform projects" that are capable of meeting the needs of a core group of customers but are easily modified into derivatives through addition, substitution and removal of features. McGrath [4] also stresses the need for a well-designed product platform for a family of products. Karhinen et al. [6] address the issue of developing software product families, which share effort and reuse parts. Parts commonality has been viewed as a means of cost reduction. Previous researchers [7-11] have shown that part commonality can help minimize inventory investment while maintaining a desired level of customer service. McDermott and Stock [12] in their paper describe how the use of common parts can shorten the product development cycle for savings in both time and money in the manufacturing process. Collier $[9,10]$ proposed an analytical measure of product structure called the degree of commonality index.

Having a common assembly and manufacturing process is another important aspect of developing common product platforms. MacDuffie et al. [13] looked at how variety affected manufacturing within the automotive industry by studying empirical data; he reported that part complexity has a negative impact on productivity. Stadzisz and Henrioud [14] describe a methodology for the integrated design of product families and assembly processes through the use of web grammars [15]. Siddique and Rosen $[16,17]$ have investigated use of graph grammars and combinatorial design spaces for configuration reasoning of product platforms. Other researchers [18-21] recommend the concept of postponement or late point differentiation, which was first introduced in the marketing literature by Alderson [22]. The concept of postponement suggests that the practice of redesigning the product or the production process to delay the point of differentiation as much as possible. Chen et al. [23] suggests designing flexible product architectures to enable small product changes to increase product variety. Although researchers have highlighted the advantages of product family design, process for estimating cost benefits for moving towards a product platform approach has not received considerable focus.

\subsection{Activity Based Costing}

Activity Based Costing (ABC) is based on the idea that activities consume resources and products consume activities. The cost of product is then the sum of costs of activities associated with the product. The usage of $A B C$ is gaining popularity over conventional costing systems [24] - initially because of its more correct cost assessments. In $\mathrm{ABC}$, costs are assigned to products based on the resources they consume. The costs of all activities are traced to the product for which they are performed. Overhead costs are also traced to a particular product rather than spread arbitrarily across all product lines. An ABC system gives visibility to how effectively resources are being used and how all activities contribute to the cost of a product.

Estimating cost for a new family of products using a platform approach has associated uncertainty with it, which needs to be included in the ABC model. Emblemsvag and Bras [25] have used combination of $\mathrm{ABC}$ and modeling of uncertainty as continuous and discrete probability distributions. In their method, the uncertainty is handled by modeling uncertainty as fuzzy numbers. The Monte Carlo simulation technique is then used to solve the model and to determine the effects of uncertainty on cost. In this paper we employ a similar procedure to develop and solve the cost models for family of products.

\section{Development of Cost Model for Family of Products}

Our approach to developing a cost model for platform approach is illustrated in Figure 1. The process consists of five steps to model the problem and then to solve it. The output from the model, after it has been solved, is the cost estimate for implementing a product platform approach for a family of products. It is assumed that (1) the company has knowledge about the current market, which includes market segmentation and requirements for each segment, and (2) the company is looking into employing a platform approach to satisfy multiple market segments.

The problem formulation that corresponds with development of the cost model for a family of products is shown below:

Given: Existing product family approach, activities involved in development and manufacturing of the product family, uncertainty involved in cost and time for each activity, new platform approach for the product family.

Identify: Activities involved in development and manufacturing of the new product family approach, uncertainty involved in cost and time for each activity for the new platform approach.

Formulate: ABC models for existing and new product family approach. 
Simulate: ABC models for statistical data related to existing and new product family approaches.

Test Hypothesis.

Select: Platform approach with better financial outcome.

The five steps utilized for developing and solving the cost model formulation are described next.
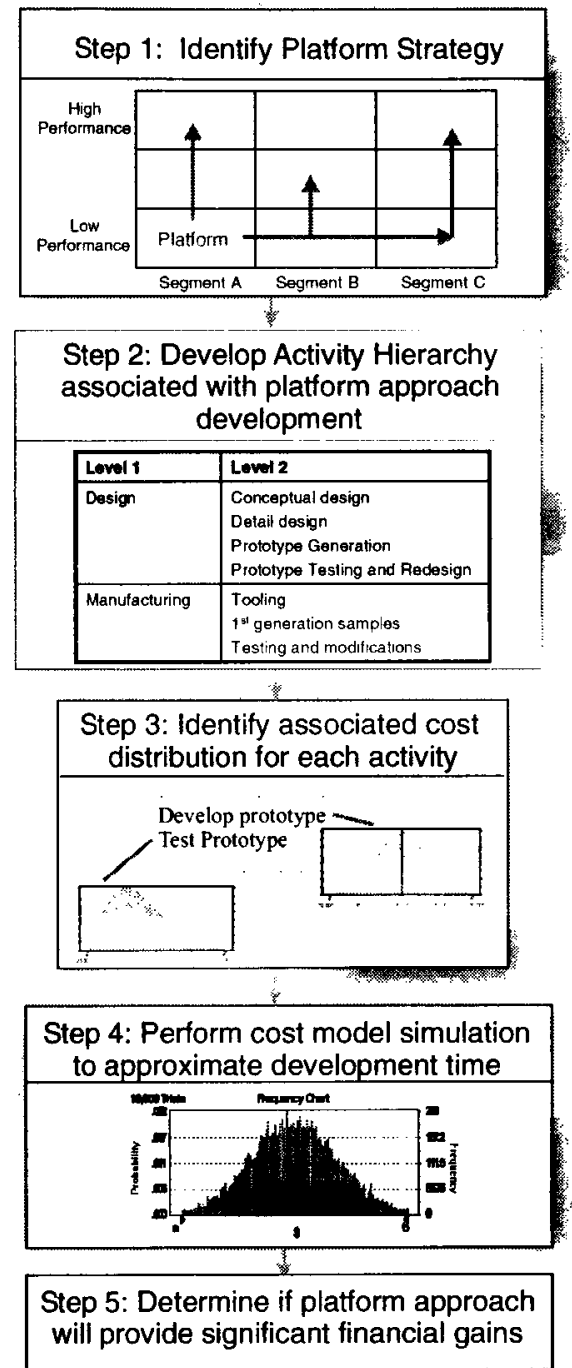

Figure 1. Steps for generating $A B C$ model for product family.

\section{Step 1: Identify Platform Strategy}

Develop a platform leveraging strategy for the product family utilizing a market segmentation grid [26]. The market segmentation grid developed by Meyer [27] facilitates identifying leveraging strategies for a product platform. In a market segmentation grid, the major market segments serviced by a company's products are listed horizontally in the grid. The vertical axis reflects different tiers of price and performance within each market segment. Several example instantiations of this grid can be found in $[27,28]$ for companies such as Hewlett Packard, Compaq, Steelcase, and Herman Miller. Three types of platform leveraging strategies can be identified within the market segmentation grid (Figure 2): In Horizontal leveraging, subsystems within a product family are leveraged from one market segment to the next for a given price/performance tier. During Vertical leveraging, a product platform is leveraged to address a range of price/ performance tiers within a specific market segment. During Beachhead approach, horizontal and vertical leveraging is combined to achieve perhaps the most powerful platform leveraging strategy. The market segmentation grid is utilized in later steps to aggregate cost for platform and family members to estimate development cost associated with the entire product family. This step corresponds to organizing some of the information provided in the "Given" of the formulation.

\section{Step 2: Develop Activity Hierarchy Associated with Platform Approach}

The activity model(s) are generated by employing the simple approach of creating activity hierarchies. Development of the activity hierarchy for the product platform approach is divided into two sub-steps. In the first sub-step, the activity hierarchy of single product development process is generated. This step is performed because usually a company has well-established procedures or are knowledgeable about activities involved in developing single products. In the second sub-step, the single product activity hierarchy is

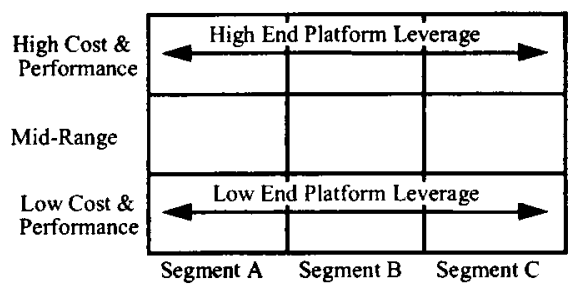

(a) Horizontal Leveraging

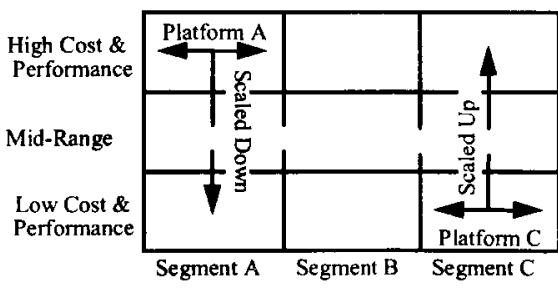

(b) Vertical Leveraging

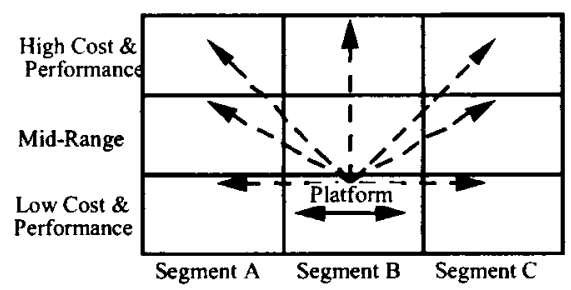

(c) Beachhead Strategy

Figure 2. Platform leveraging in the market segmentation grid. 


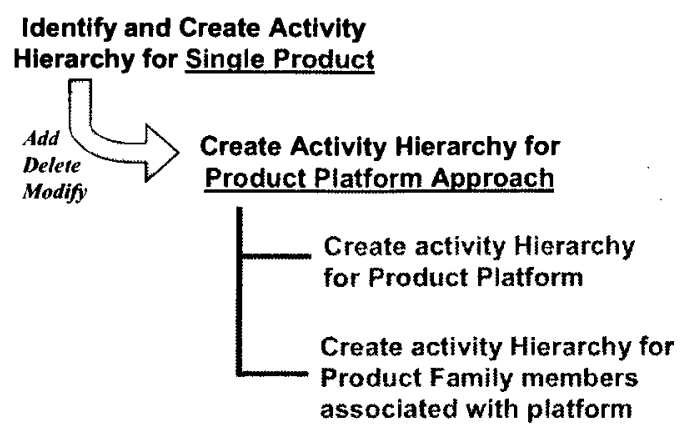

Figure 3. Development of activity hierarchy for platform approach.

modified to create a new activity hierarchy for the product family approach using a product platform (Figure 3).

When utilizing a product platform approach to develop a product family, the activities can be divided into two categories: (1) Activities associated with developing the initial platform and (2) activities associated with development of the family members from the platform. To explicitly address both of these issues the activity models for platform approach are developed in two stages (1) activity hierarchy for initial platform and (2) activity hierarchy for subsequent family members. Starting point for both the hierarchy models is the single product hierarchy model, which is modified/extended to better capture the product development process using a platform approach. Step 2 corresponds to "Identify" of the problem formulation.

\section{Step 3: Identify Associated Cost Distribution for Each Activity}

Cost associated with each activity has variability associated with it, which needs to be included in the model. In this paper, activity costs are represented as probability distributions. Uncertainty in cost, associated with the activities, is modeled based on experience from engineering and finance, because cost data associated with activities related to development of single product or product family are not available. The type of distribution to use, the mean, the left deviation, and the right deviation are modeled based on experience. These distributions are assigned to appropriate numbers that have uncertainty associated with them.

With the cost distribution information, regarding each activity, identified the $\mathrm{ABC}$ model can be developed. Development of the cost model for the platform approach follows the same overall procedure as the activity hierarchy development (described in step 2) - (1) estimating cost distribution for single product development activities and (2) modifying these estimations for initial platform and subsequent products from the platform. Step 3 of the overall process corresponds to utilizing information from "Identify" to perform the "Formulate" task of the problem formulation.

\section{Step 4: Perform Simulation to Approximate Development Cost}

In this step, cost is estimated by simulating models developed in Step 3. Cost model for entire product family, using a platform approach, can be estimated as follows:

$$
\mathrm{F}_{\text {cost }}=\mathrm{P}_{\text {cost }}+n \times \mathrm{M}_{\text {cost }}
$$

where

$\mathrm{F}_{\text {cost }}=$ Cost for entire product family

$\mathrm{P}_{\text {cost }}=$ Development cost for initial product platform

$\mathbf{M}_{\text {cost }}=$ Development cost for product family members from platform

$n=$ Number of family members excluding initial platform.

Cost model developed for single products is simulated to estimate development cost for single products. The estimated cost for developing the product family without using platform approach $\left(\mathbf{S}_{\text {cost }}\right)$ is estimated by multiplying the cost estimate for a single product $\left(\mathrm{Sp}_{\mathrm{cost}}\right)$ with the number of members in the family.

$$
\mathrm{S}_{\mathrm{cost}}=(n+1) \times \mathrm{Sp}_{\mathrm{cost}}
$$

where, $n$ is as before.

The cost/saving for utilizing a platform approach is estimated as:

$$
\mathbf{F}_{\text {cost }}-\mathbf{S}_{\text {cost }}
$$

In this paper Monte Carlo simulation technique is used to determine the effects of the uncertainties in the final cost for the product family. To solve the model using Monte Carlo simulation, the Crystal Ball software is used, which adds on to Microsoft Excel. The Monte Carlo simulation provides random samples of numbers from the assumed probability distributions. These random numbers then propagate through relationships/equations in the model to estimate the desired final output, which is development cost for this paper. This step corresponds to "Simulate" of the problem formulation.

\section{Step 5: Determine Approach with Better Financial Prospect}

When the trials for the simulation have been performed, the final output forms a new statistical distribution. Due to the randomness of the numbers for the assumptions propagated through the model, it can be used in ordinary statistical analysis. Using the cost 
data from existing and platform approach, decision regarding selection of the new approach can be performed. The decision maker is concerned with identifying if the potential cost savings will be more than a specified amount $(\delta)$, given a specified confidence level. The question can be answered utilizing hypothesis testing. The null hypothesis of interest is:

$$
\begin{aligned}
& H_{0}: \mu_{1}-\mu_{2}=\delta \\
& H_{1}: \mu_{1}-\mu_{2}>\delta
\end{aligned}
$$

where $\mu_{1}$ corresponds to the mean of the existing approach and $\mu_{2}$ corresponds to the mean of platform approach.

In our approach we use large and same number samples for the model simulations. With these conditions the test statistic becomes:

$$
z=\frac{\left(\bar{x}_{1}-\bar{x}_{2}\right)-\delta}{\sqrt{\left(\sigma_{1}^{2}+\sigma_{2}^{2}\right) / n}}
$$

where $n$ is the number of samples for the simulations.

The null hypothesis in this case will be rejected if $z>z_{\alpha}$, where $\alpha$ is the confidence level.

\section{Case Study - Development of Motor Family}

The computer storage industry has grown rapidly with increase in computer usage and storage demands. With the advent of personal computers and computer applications in various fields, new markets have opened up for data storage. With the constantly changing demands of computer industry and the existing competitions among the different manufacturers, time cycle needed for hard disk development is decreasing and have become a never-ending challenge to the disk drive manufacturers. In addition, the competition of bringing the products into market at an earlier time than competitors is creating urgency in every new product release. These needs and challenges in the hard disk drive industry are forcing manufacturers to implement product platform concepts. Manufacturers are trying to implement platform approach for components and modules of the hard disks. To make rational decisions on modules/components that should utilize a platform approach, for a set of products, manufacturers need to identify potential investment outcome, which includes reduction in development cost.

\subsection{Case Scenario}

One of the hard disk performance measures is the revolution speed of the spindle motor. The spindle motor of the hard disk drive is responsible for rotating the hard disk platters, allowing the hard disk drive to operate. Increasing performance and demand of storage capacity has increased the spinning speeds of the spindle. With the increased speed the data can be read faster from the recorded media and thus quicken the operations of hard disk drive. Based on the speed of spindle motor, the hard disk drive market can be segmented for both consumer (PC) and Desktop drives.

The spindle motors also need to meet certain specifications. First of all the motor should be of high quality to run for thousands of hours with start and stop cycles without failures. Secondly, it must not generate particles or heat or noise while operating over a period of time. Thirdly, it must be smooth and less vibrating. This is needed as the tolerances between the media and head are too low, which if not maintained will affect the data. Finally, it should able to run at constant speed. The spindle motor has a base with vertical cylindrical hub (Figure 4). This hub holds the platters and rotates it at constant speed, whenever computer is operating. The spindle motor is fixed to the base plate of the hard disk drive during assembly. Most disk drives have several disks that are separated by disk spacers and are clamped to the rotating spindle by means of screws. The spindle, and consequently the disks, are rotated at a constant speed, usually disk drive speeds range from 4200 to $12000 \mathrm{rpm}$.

Based on the market needs and demands three new sets of hard disks, with varying speeds, will be introduced. The speeds for the different sets of hard disks are:

1. Consumer Drive with $4200 \mathrm{rpm}(\mathrm{CD}-1)$

2. Desktop Drive with $5400 \mathrm{rpm}$ (DD-1)

3. Desktop Drive with 7200 rpm (DD-2)

These disk drives will be introduced in the market over a period of time. The spindle motors used in these drives have the potential to be manufactured from the same motor platform, which is being considered by the manufacturer. The consumer drive motor (CD-1) will be

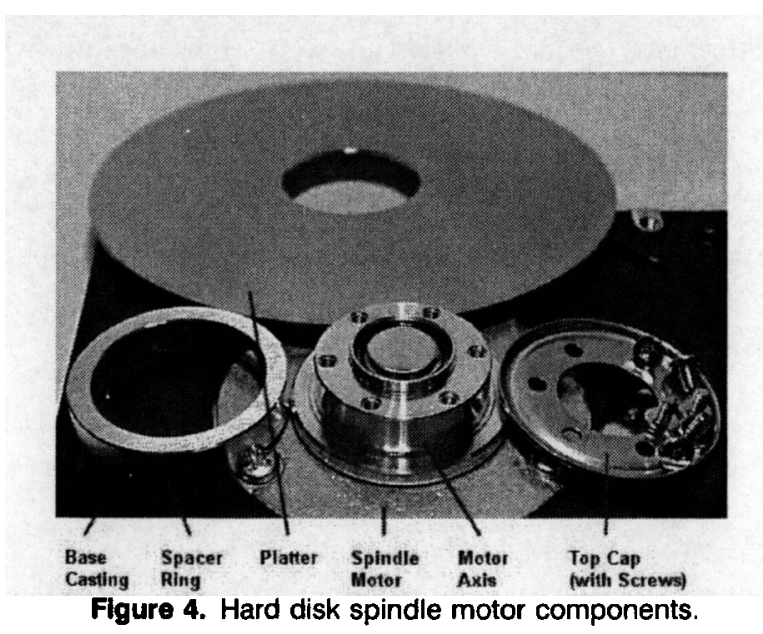


first developed and DD-1 and DD-2 will leverage the spindle motor of CD-1. To make the decision of using a platform approach, the manufacturer wants to identify the possible advantages over developing the products separately.

One of the related questions that need to be answered is: What will be the financial gain by using one platform for the three spindle motors?

To make the move towards a platform approach, the company wants to know if there will be a savings of at least 2.25 million dollars for launching the new program. If the cost saving is less than the specified target amount then the motors for the three drives will be developed individually. It has been assumed that the technical problems associated with providing different speeds for the motor can be solved.

\subsection{Cost Model}

\section{STEP 1: PLATFORM STRATEGY FOR MOTOR FAMILY}

The platform strategy for the motor is shown in Figure 5 . The initial platform for the motor family will be the motor used in CD-1 drive. The motor for the desktop drives, DD-1 and DD-2, will be developed from the initial platform. Hence, spindle motors used in the DD-1 and DD-2 disk drives are family members supported by CD-1 motor platform.

\section{STEP 2: DEVELOP ACTIVITY HIERARCHY}

Activities associated with new motor development includes both: (1) Component Level and (2) Drive Level activities. Drive Level activities include engineering and testing to determine system level compatibility of the motor. Component level activities include costs associated with development of the motor excluding drive level activities.

Activity hierarchy for current single motor development process, which is gathered from designers and engineers, is shown in Table 1. Single spindle motor development process activities were then modified by engineers and designers for initial platform and sub-

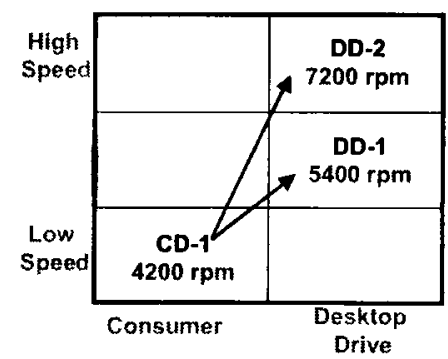

Figure 5. Product platform approach for spindle motor product family. sequent spindle motor family members. The activity hierarchy for the initial motor development process and single motor development process (without platform) were determined to be the same. The activities involved in developing subsequent spindle motors from the platform are shown in Table 2.

\section{STEP 3: IDENTIFY ASSOCIATED COST DISTRIBUTION FOR EACH ACTIVITY}

With the activities related to spindle motor development process for both single and platform approach identified, cost associated with each activity is added to complete the models. The labor cost has been calculated with an approximate salary of $\$ 10,000$ per month.

Uncertainty has been included for all the activities in the activity hierarchy for single product development process. For example, for the "Engineering Design" at the component level, the hours required to perform the activity can vary from 80 to $120 \mathrm{~h}$, with the possibility that on average the hours spent will be close to the

Table 1. Actlvity hierarchy for indlvidual motor development.

\begin{tabular}{|c|c|}
\hline Level 1 & Level 2 \\
\hline \multicolumn{2}{|l|}{ Component Level Activities } \\
\hline $\begin{array}{ccc}\text { Design Phase } & & \\
& \ddots & \\
& \because & \ddots\end{array}$ & $\begin{array}{l}\text { Engineering Design } \\
\text { Generate 1st Eng. Samples } \\
\text { Test and Redesign } \\
\text { Generate 2nd Eng. Samples } \\
\text { Sample test }\end{array}$ \\
\hline Gen 1 Motors: & $\begin{array}{l}\text { Samples } \\
\text { Tooling } \\
\text { Engineer (Test) }\end{array}$ \\
\hline Gen 2 Motors: & $\begin{array}{l}\text { Samples } \\
\text { Engineer (Test) }\end{array}$ \\
\hline Factory Test & Factory Test \\
\hline Gen Test & Gen Test \\
\hline Customer Support & Customer Support \\
\hline $\begin{array}{l}\text { Drive Level Activities } \\
\text { Engineer }\end{array}$ & $\begin{array}{l}\text { Drive Package Design } \\
\text { Documentation }\end{array}$ \\
\hline Engineering Failure Analysis & Engineering Failure Analysis \\
\hline Gen 1: & $\begin{array}{l}\text { Engineering } \\
\text { Quality (Reliability) } \\
\text { Quality (Performance) } \\
\text { Materials } \\
\text { Launch }\end{array}$ \\
\hline Gen 2: & $\begin{array}{l}\text { Engineering } \\
\text { Quality (Reliability) } \\
\text { Quality (Performance) } \\
\text { Materials } \\
\text { Launch }\end{array}$ \\
\hline Customer Support & Engineer \\
\hline Factory Reliability Eng. Test & Factory Reliability Eng. Test \\
\hline Sustaining Engineer & Sustaining Engineer \\
\hline
\end{tabular}


minimum. A Weibull distribution was chosen, by the designers and engineers to reflect the uncertainty involved in the parameter. Scale and Shape parameters for the distribution are shown in Figure 6.

Distribution Parameters associated with uncertainty for different activities for component level activities are shown in Table 3. The ranges are given in hours for labor, dollar for cost and number of items for other activities.

With the model for single product development specified, cost model for implementing the platform approach is completed. The initial platform model is same as the single platform development approach. Distribution associated with activities involved in product family member development, is estimated from single product development data. The probability distributions for activities involved at the component level for spindle motor family members are presented in the third column of Table 3.

\section{STEP 4: SIMULATE MODEL TO APPROXIMATE COST}

The development cost for the entire spindle motor family is estimated by simulating development cost models for the initial motor platform, CD-1, and members of the product family, DD-1 and DD-2. Addition of these costs gives an approximation for the

Table 2. Activity hlerarchy for family member motor development.

\begin{tabular}{|c|c|}
\hline Level 1 & Level 2 \\
\hline \multicolumn{2}{|l|}{ Component Level Activities } \\
\hline \multirow[t]{3}{*}{ Gen 1 Motors: } & Samples \\
\hline & Tooling \\
\hline & Engineer (Test) \\
\hline \multirow[t]{2}{*}{ Gen 2 Motors: } & Samples \\
\hline & Engineer (Test) \\
\hline Factory Test & Factory Test \\
\hline Gen Test & Gen Test \\
\hline Customer Support & Customer Support \\
\hline \multicolumn{2}{|l|}{ Drive Level Activities } \\
\hline \multirow{2}{*}{ Engineer } & Drive (package) \\
\hline & Documentation \\
\hline \multirow[t]{5}{*}{ Gen 1: } & Engineering \\
\hline & Quality (Reliability) \\
\hline & Quality (Performance) \\
\hline & Materials \\
\hline & Launch \\
\hline \multirow[t]{5}{*}{ Gen 2: } & Engineering \\
\hline & Quality (Reliability) \\
\hline & Quality (Performance) \\
\hline & Materials \\
\hline & Launch \\
\hline Customer Support & Engineer \\
\hline Factory Reliability Eng. Test & Factory Reliability Eng. Test \\
\hline Sustaining Engineer & Sustaining Engineer \\
\hline
\end{tabular}

total development cost for the family using a platform approach. The estimated total cost for developing the spindle motors individually is obtained by running three cost models, representing each spindle motor simultaneously and then adding the development costs. In the case of using the platform approach, total cost is approximated by estimating the cost of developing the initial platform (CD-1) and the two motors of the family (DD-1 and DD-2).

To demonstrate the applicability of the model a simulation is run on the entire model and preliminary results are obtained. Statistics for Total Cost without Platform, Total Cost with Platform and Total Cost Savings are shown in Table 4 . The mean total cost saving for implementing a platform approach using the CD-1 as the platform and then developing DD-1 and DD-2 from CD-1, instead of developing the spindle motors separately, is almost 2.3 million dollars.

Frequency distribution for total cost savings is shown in Figure 7. The simulation data can be used to perform percentile calculations and other statistical analysis to help decide the financial gains in implementing a platform approach for the three spindle motors.

\section{STEP 5: DETERMINE APPROACH WITH BETTER FINANCIAL PROSPECT}

From the requirements of the problem, the management wants to know if there will be a cost savings of at least $\$ 2.25$ million. The hypotheses for the development of the three spindle motors development problem can be formulated as:

$$
\begin{aligned}
& H_{0}: \mu_{1}-\mu_{2}=2.25 \times 10^{6} \\
& H_{1}: \mu_{1}-\mu_{2}>2.25 \times 10^{6}
\end{aligned}
$$

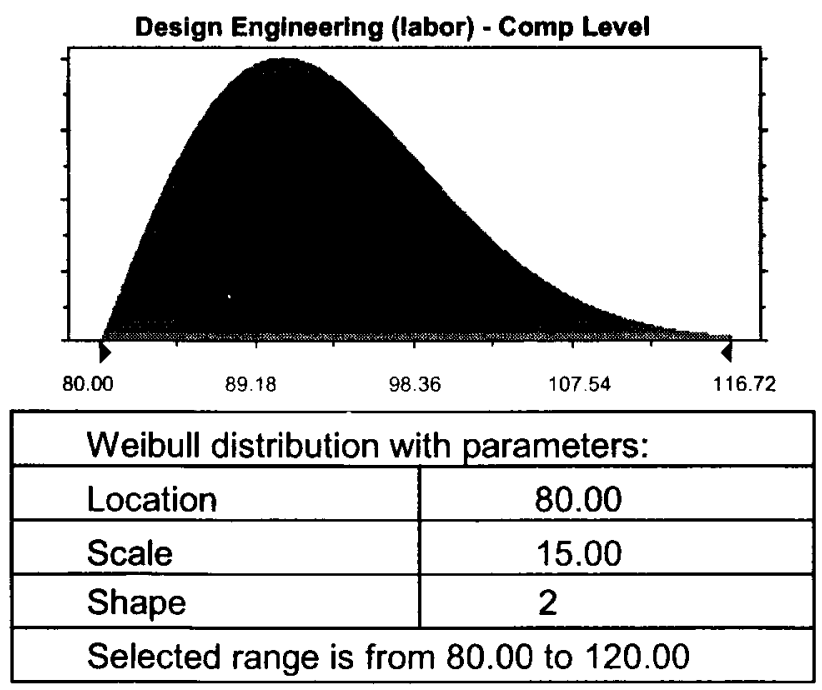

Figure 6. Weibull distribution associated with Engineering Design (labor) parameter for component level. 
Table 3. Range for motor development parameters at component level.

\begin{tabular}{|c|c|c|}
\hline $\begin{array}{l}\text { Motor development } \\
\text { parameters }\end{array}$ & $\begin{array}{l}\text { Single product and } \\
\text { Initial platform }\end{array}$ & $\begin{array}{l}\text { Subsequent } \\
\text { family members }\end{array}$ \\
\hline Engineering Design [labor] & $80-120(h)$ & \\
\hline 1st Eng Sample Cost & 20-32 (samples) & \\
\hline 1st Eng Sample Test [labor] & $160-240(h)$ & $\therefore$ \\
\hline 2nd Eng Sample Cost & 100-150 (samples) & \\
\hline 2nd Eng Sample Test [labor] & $80-120(h)$ & $\cdots$ \\
\hline Gen 1 Sample Cost & $500-600$ (samples) & 100-200 (samples) \\
\hline Gen 1 Factory Tooling Cost & $\$ 250 \mathrm{~K}-\$ 300 \mathrm{~K}$ & $\$ 20 \mathrm{~K}-\$ 80 \mathrm{~K}$ \\
\hline Gen 1 Sample Test [labor] & $80-120(h)$ & $40-65(h)$ \\
\hline Gen 2 Sample Test [labor] & $480-580(h)$ & $240-340(h)$ \\
\hline Gen 2 Sample Cost & $7500-8000$ (samples) & 3000-3500 (samples) \\
\hline Factory Test [labor] & $10000-12500$ (samples) & 5000-6250 (samples) \\
\hline Gen Test [labor] & $480-520(h)$ & $200-225(h)$ \\
\hline Customer Support [labor] & $300-400(h)$ & $200-275$ (h) \\
\hline
\end{tabular}

Table 4. Simulation results for entire model.

\begin{tabular}{lrrr}
\hline & $\begin{array}{c}\text { Total } \\
\text { Cost w/o } \\
\text { Platform }\end{array}$ & $\begin{array}{c}\text { Total Cost } \\
\text { with } \\
\text { Platform }\end{array}$ & $\begin{array}{r}\text { Total } \\
\text { Cost } \\
\text { Savings }\end{array}$ \\
\hline Mean & 4298654 & 2002300 & 2296354 \\
Median & 4297340 & 2001331 & 2295994 \\
Standard Deviation & 36540 & 27132 & 45472 \\
\hline
\end{tabular}

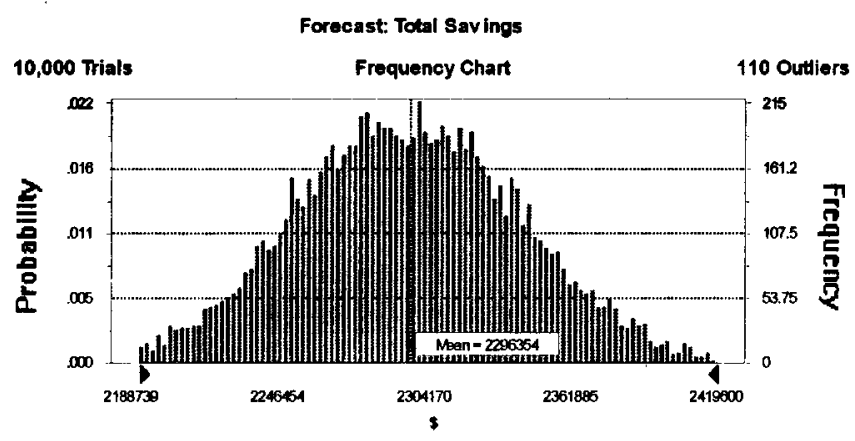

Figure 7. Frequency chart for total cost savings.

where $\mu_{1}$ corresponds to the mean of the existing approach and $\mu_{2}$ corresponds to the mean of platform approach.

The hypothesis will be tested for both $90 \%$ and $99 \%$ confidence level. Using statistical data from Table 4:

$$
z=101.09
$$

From statistical tables: $z_{0.10}=1.282$ and $z_{0.01}=2.326$. For both confidence levels, the null hypothesis is rejected because $z>z_{\alpha}$. Hence it can be stated that with $99 \%$ confidence, for the cost model developed, the platform approach will yield at least 2.25 million dollar savings.

\section{Conclusion}

In the present global market high quality, reduced cost and development time are some of the challenges facing the manufacturers. Development of product platform to support a family of products can reduce cost and development time for products. To move towards a platform approach, manufacturers need to estimate development cost for product families and potential cost savings. The ABC model was developed to assist designers/management in making decisions regarding implementation of product platform approach. The cost estimates for platform approach were compared with existing single product development approach to determine possible financial gains. The developed cost models incorporated uncertainty associated with development cost of product. The addition of uncertainty is incorporated in the model using fuzzy numbers and then employing Monte Carlo simulation to simulate the models. The activity hierarchy, developed for the cost models, also provided information on the process of developing new products and platform approach.

The method of developing the cost model for the platform approach was demonstrated using a family of Hard Disk drive spindle motors. Statistical results, which included frequency chart, quartile calculations and other data, associated with the model were calculated by simulating the model using Monte Carlo simulation. The simulated data were then used to determine if the platform approach meets a specified cost saving. The statistical data were used to better understand the cost associated with platform development and potential cost savings. The statistical data can also be used to identify cost drivers associated with the specific product development to reduce cost.

The current cost model only addresses development cost, other life cycle costs associated with developing 
product platforms need to be added to better estimate the effect of utilizing a platform approach. For example, in most cases, utilizing a platform approach reduces product development time and eventually time to market new products, which brings substantial financial gain.

\section{References}

1. Bower, J.L. and Hout, T. (1988). Fast cycle capability for competitive power. Harvard Business Review, 66: $110-118$.

2. Stalk, G.J. and Hout, T. (1990). Competing Against Time. New York: Free Press.

3. Schile, T. and Goldhar, J.D. (1989). Product variety and time based manufacturing and business management: achieving competitive advantage through CIM. Manufacturing Review, 2(1): 32-42.

4. McGrath, M.E. (1995). Product Strategy for HighTechnology Companies. New York: Irwin Professional Publishing.

5. Wheelwright, S.C. and Clark, K.B. (1992). Revolutionizing Product Development: Quantum Leaps in Speed, Efficiency and Quality. New York: The Free Press.

6. Karhinen, A., Ran, A. and Tallgren, T. (1997). Configuration design for resue. In: Proceedings of the 1997 IEEE 19th International Conference on Software Engineering. Boston, MA.

7. Baker, K.R. (1985). Safety stocks and component commonality. Journal of Operations Management, 6(1): 13-22.

8. Baker, K.R., Magazine, M.J. and Nuttle, H.L.W. (1986). The effect of commonality of safety stock in a simple inventory model. Management Science, 3(8): 982-988.

9. Collier, D.A. (1981). The measurement and operating benefits of components part commonality. Decision Sciences, 12(1): 85-96.

10. Collier, D.A. (1982). Aggregate safety stock levels and component part commonality. Management Science, 28(22): 1296-1303.

11. Guerrero, H. (1985). The effect of various production strategies on product structures with commonality. Journal of operations management, 5(4): 395-410.

12. McDermott, C.M. and Stock, G.N. (1994). The use of common parts and designs in high-tech industries: a strategic approach. Production and Inventory Management Journal, 35(3): 65-68.

13. MacDuffie, J.P., Sethuraman, K. and Fisher, M.L. (1996). Product variety and manufacturing performance: Evidence from the international automotive assembly plant study. Management Science, 42: 350-369.

14. Stadzisz, P.C. and Henrioud, J.M. (1995). Integrated design of product families and assembly systems. IEEE International Conference on Robotics and Automation. Nagoya, Aichi, Japan. pp. 1290-1295.

15. Pfaltz, J.L. and Rosenfeld, A. (1969). Web Grammars. Proceedings of First International Joint Conference on Artificial Intelligence. Washington, D.C. pp. 609-619.

16. Siddique, Z. and Rosen, D.W. (2000). Product family configuration reasoning using discrete design spaces. 2000
ASME Design Engineering Technical Conference, Baltimore, Maryland, paper no. DETC99/DTM-14666.

17. Siddique, Z. and Rosen, D.W. (1999). Product family design: a graph grammar approach. 1999 ASME Design Engineering Technical Conference, Las Vegas, Nevada, paper no. DETC99/DTM-8762.

18. Ishii, K., Juengel, C. and Eubanks, F. (1995). Design for product variety: key to product line structuring. $A S M E$ Design theory and methodology Conference. Boston, MA. pp. $499-506$.

19. Lee, H.L. and Billington, C. (1994). Designing products and processes for postponement. In: Dasu, S. and Eastman, C. (eds.), Management of Design: Engineering and Management Perspective. Boston, MA: Kluwer Academic Publishers. pp. 105-122.

20. Lee, H.L. and Tang, C.S. (1997). Modeling the costs and benefits of delayed product differentiation. Management Science, 43(1): 40-53.

21. Martin, M.V. and Ishii, K. (1996). Design for variety: a methodology for understanding the costs of product proliferation. 1996 ASME Design Engineering Technical Conferences. Irvine, CA, 96-DETC/DTM-1610.

22. Alderson, W. (September 1950). Marketing efficiency and the principle of postponement. Cost and profit outlook, p. 3.

23. Chen, W., Rosen, D., Allen, J. and Mistree, F. (1994). Modularity and the independence of functional requirements in designing complex systems. Concurrent Product Design, 74: 31-38.

24. Cooper, R. (September 1989). ABC: A need, not an option. Accountancy, pp. 86-88.

25. Emblemsvåg, J. and Bras, B.A. (1994). Activity-based costing in design for product retirement. In: Proceedings 1994 ASME Advances in Design Automation Conference, Minneapolis, 351-362.

26. Meyer, M.H. and Lehnerd, A.P. (1997). The Power of Product Platforms. New York, NY: The Free Press.

27. Meyer, M.H. (1997). Revitalize your product lines through continuous platform renewal. Research Technology Management, 40(2): 17-28.

28. Meyer, M.H., Tertzakian, P. and Utterback, J.M. (1997). Metrics for managing research and development in the context of the product family. Manage Sci., 43(1): 88-111.

\section{Zahed Siddique}

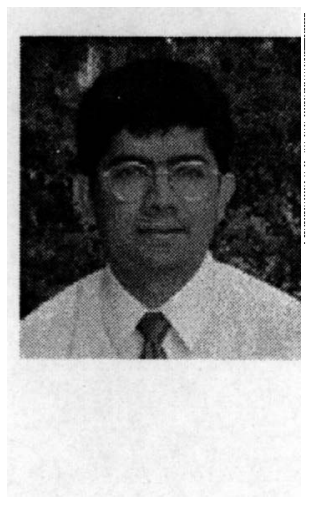

Zahed Siddique is an assistant professor at School of Aerospace and Mechanical Engineering at University of Oklahoma. His research interests include product family design, configuration design, internet based design, designing for life-cycle considerations, and development of tools for such activities. He received his Ph.D. from Georgia Institute of Technology in 2000. 


\section{Bill Repphun}

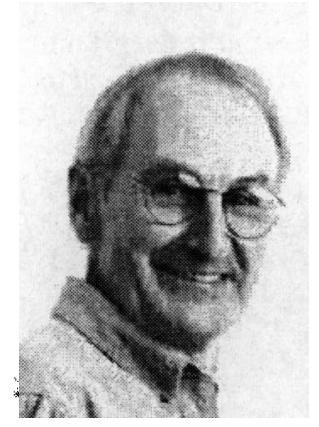

Bill Repphun is the Chief Technologist of the Mechanical Research and Development, Advanced Concepts group at Seagate Technologies, Inc. Bill has over 20 years of disc drive design experience and 13 years in the automobile business. Bill is a big fan of simple and elegant designs, Bill strongly influences thinking in all of Seagate's design centers. Bill, is a graduate of the University of Wisconsin, Madison, holds six patents. Prior to joining Seagate, he worked at Conner Peripherals, Miniscribe and General Motors. 